Fecha de recepción: julio 2014

Fecha de aceptación: marzo 2015

Versión final: marzo 2016

\section{La fotografía en la moda. Entre la seducción y el encanto}

Mónica Silvia Incorvaia *

Resumen: Así como la invención de la fotografía cambió la mirada de la sociedad, su irrupción en la moda permitió visualizar un mundo de refinamiento que las mujeres del siglo XX contemplaron admiradas. Con el advenimiento de la prensa gráfica, y ante la llegada de revistas destinadas a un público específico, los fotógrafos tuvieron la posibilidad no solo de dar a conocer sus propias capacidades profesionales, sino de dotar a la indumentaria de imágenes donde lo artístico y el glamour se mostraron en toda su dimensión. Nombres como los de Edward Steichen, Man Ray, Helmut Newton, Richard Avedon, entre otros, posibilitaron mostrar su talento, inspirados en las corrientes artísticas que surgieron en la primera mitad del siglo XX y se prolongan hasta la actualidad. Este trabajo analiza sus respectivas obras en relación con la estructura de sus imágenes y las diferentes características de sus propuestas.

Palabras clave: moda - glamour - fotografía - prensa gráfica - vanguardias - estética.

[Resúmenes en inglés y portugués en la página 38]

${ }^{(*)}$ Master en Cultura Argentina (Ediac - Fondo Nacional de las Artes). Prof. de Seminario II e Historia de la Fotografía, Universidad de Palermo. Historia de la Fotografía, Lenguaje Publicitario y Periodístico en Nueva Escuela de Diseño y Comunicación.

El fotógrafo transforma el momento de la vida en el reposo de la forma. El contemplador de una fotografía transforma, por su parte, gracias a su fuerza imaginaria, el reposo de la forma en vida, en movimiento .... (Willie Baumeister)

Así como la invención de la fotografía cambió la mirada del mundo con su nacimiento ocurrido en 1839, su irrupción en el universo de la moda muchos años después, permitió visualizar una sociedad plagada de refinamiento y estética que especialmente las mujeres del siglo XX contemplaron admiradas. Precisamente hasta ese siglo la moda se presentaba 
a través de "figurines" o periódicos ilustrados que daban cuenta de los últimos estilos en vestuario femenino.

Las primeras publicaciones que apelan al dibujo para difundir estas corrientes datan del siglo XVIII, cuando aparece en Inglaterra en 1875 Lady Journal y posteriormente en Francia Le Journal de dames. Hacia 1869 se edita en ese país Le courrier de la mode, que destacaba los diseños de la época y los peinados que los acompañaban.

Durante el siglo XIX títulos tales como L'Observateur de la mode (1818) o La Mode, publicada en 1869, fueron referentes ineludibles de los nuevos estilos.

Con el advenimiento de la prensa gráfica, y ante la llegada de revistas destinadas a un público específico, los fotógrafos tuvieron la posibilidad no solo de dar a conocer sus propias capacidades profesionales, sino de dotar a la indumentaria de imágenes donde lo artístico y el glamour se mostraron en toda su dimensión.

Estos elementos acompañan el criterio del sentido de la belleza, unido indisolublemente a este paradigma, considerando las épocas y las estéticas correspondientes.

La Antigüedad denomina bello en el lenguaje cotidiano lo que es valorado positivamente, lo que gusta, resulta atractivo, tiene una apariencia complaciente o despierta admiración. Se llama bello a lo viviente, pero también a lo honorable o a lo útil. (Henckmann, Lotter, 1998, p. 30)

Dentro de este panorama, nombres como los de Adolph de Meyer, Edward Steichen, Man Ray, Martin Munkacsi, Toni Fissell, Helmut Newton, Richard Avedon, entre otros, posibilitaron mostrar todo su talento, a través de las publicaciones de moda más difundidas, inspirados en las corrientes artísticas que surgieron en la primera mitad del siglo XX y se prolongaron por su estilo y mensaje.

Este trabajo analizará sus respectivas obras en relación con la composición y la estructura de sus imágenes y los medios para los que trabajaron. Así se podrá apreciar la elaboración de los recursos expresivos que hicieron de estos artistas los referentes de la fotografía actual de moda.

La fotografía representa el instrumento de expresión visual idóneo para la moda. El triunfo de este medio, al que la prensa popular con sus tiradas de millones de ejemplares imprimió un extraordinario impulso, amplió de forma considerable el campo de acción de la moda. La fotografía y la moda tienen además otro punto en común. Se podría decir que la moda ofrece a la fugacidad del instante la posibilidad de materializarse de alguna manera en el devenir del tiempo; la fotografía muestra el instante en un pasado irrecuperable. La moda y la fotografía se complementan mutuamente. (Ruhberg et. alt, 1989, p. 651).

Si bien la fotografía plantea su omnipresente espacio en toda manifestación humana, la imagen en la moda alcanza un valor superlativo porque representa los anhelos y deseos de "ver" y "verse" reflejado de la mejor forma posible. 
Se considera que al igual que la fotografía, la moda nace en París, si bien, como ya se planteó, esta última lo hace mucho tiempo antes. Pero será la gráfica la que le dará su identidad y permitirá difundir los dictámenes de los diseñadores más afamados.

De este modo, la combinación moda-fotografía genera lo que se conoce como la "cultura de la moda", con basamentos en aspectos específicos, tales como lo que apunta Alberto Oliva en el fascículo 1 de la serie El gran libro de la moda de Clarín: “... los diseñadores que idean y fabrican la ropa, las modelos que se convierten en la cara visible de las prendas, los fotógrafos que registran el fenómeno, las revistas que la difunden y las tiendas que las venden". (2011, p. 13)

Sutileza, encanto, seducción son algunos de los adjetivos que caracterizan este rubro, hoy "coptado" por el photoshop y sus recursos tecnológicos.

\section{La moda a través de la gráfica}

La industria gráfica tuvo su mayor difusión entre fines del siglo XIX y principios del siglo $\mathrm{XX}$, lo que posibilitó la impresión de fotografía y texto en una misma plancha, generando la aparición de revistas dedicadas a la moda que trascendieron por imponer tendencia a través de diseñadores consagrados y fotógrafos destacados.

En este caso, se toma como referencia a Harper's Bazaar (1867), Vogue (1892) y Vanity Fair (1913), por ser éstas las que mayor difusión han tenido desde su publicación. Aunque, con el transcurso de los años, otras revistas tomaron este género prácticamente en todo el mundo, permitiendo así la irrupción de nuevos diseñadores y fotógrafos.

Si bien París se perfiló como la capital de la moda, de la mano de personajes como el inefable Paul Poiret (1879-1944) considerado "el rey de la moda", Estados Unidos se convirtió en el centro de las publicaciones dedicadas a la moda, especialmente a fines del siglo XIX con el advenimiento de la era industrial y el crecimiento económico del país del norte.

De este modo Harper's Bazaar, que había dado sus primeros pasos en la segunda mitad del siglo XIX, se posiciona a principios del XX. Inicialmente como publicación semanal, empieza a editarse mensualmente a partir de 1901.

Entre los profesionales que pasaron por sus páginas, se destacan Irvin Penn, Richard Avedon, Milton Green (dedicado más a la fotografía de espectáculo), y Martin Demarchelier, por ejemplo.

En plena era industrial y ante el advenimiento de un siglo poblado de expectativas, nace hacia 1892 en los Estados Unidos la revista Vogue, de la mano del norteamericano Condé Nast (1873-1949), dueño de la editorial que lleva su nombre, y responsable de las revistas Vogue, Vanity Fair y The New York, entre otras.

A lo largo de sus 120 años de existencia, impuso un estilo que se proyectó a 16 países que la distribuyen actualmente. El life style que propició está hoy vigente como símbolo del buen vestir y de las tendencias que definen su nombre. Los diseñadores más destacados han presentado sus colecciones más afamadas. Y la fotografía estuvo presente a través de profesionales tales como Barón de Meyer, Edward Steichen, Man Ray, Martin Munkacsi, Toni Fissell, Helmut Newton, Richard Avedon, y los actuales Mario Testino, Steven Klein, Bruce Weber y Annie Leibovitz, son sus principales exponentes. 
Norberto Angeletti y Alberto Oliva en su libro In Vogue (2008) realizan un pormenorizado relato de los diseñadores y profesionales de la fotografía que pasaron por sus páginas, así como de personalidades que participaron en sus notas, tal el caso de Truman Capote, Federico Fellini, Bertrand Russell o Marcelo Mastroiani.

Vanity Fair aparece en 1913 en los Estados Unidos; perteneciente al grupo editor Condé Nast Publications, combinó cultura, moda y política en sus publicaciones. Los problemas económicos surgidos en los años 30 obligaron a su editor a cesar en su publicación. De todos modos, merece consignarse que en los años de su primera etapa fotógrafos como Edward Steichen y Man Ray realizaron producciones destacables.

Su relanzamiento se produjo en 1983 editada por Richard Locke, ex crítico literario de la revista Times. En la actualidad, inclinada más hacia el mundo del espectáculo, retrata el acontecer de la vida cotidiana en ese aspecto. Annie Leibovitz se incorporó en los años 90 realizando producciones de gran despliegue.

\section{Y los fotógrafos inmortalizaron la moda}

Los denominados criterios estéticos en la fotografía, definen pautas y épocas que sus imágenes transmiten. La fotografía de moda conlleva elementos precisos que han perdurado a lo largo de la historia. No es un género frívolo ni banal, los profesionales dedicados a este rubro deben tener en cuenta aspectos precisos para sus producciones, haciendo uso de su talento y sensibilidad.

Los nombres analizados pertenecen a un criterio de selección relacionado con la incidencia que han tenido en el panorama de la moda. No son los únicos, ya que la industria gráfica, más a partir de los años 30 expandió las publicaciones en diversidad de temas.

$\mathrm{Al}$ igual que el impacto cinematográfico, la moda estuvo siempre presente en las publicaciones específicas y también en las de información general. Los denominados magazines, la incluyeron en sus páginas por formar parte del ideario colectivo. Las contingencias del siglo XX establecieron pautas que modificaron criterios en cuanto a la indumentaria, ligada a los vaivenes económicos de cada época.

De este modo, y cada uno en su estilo, acompañaron a los realizadores para los cuales ilustraron sus diseños, unificados en el concepto de belleza que define a este rubro.

No menos importante resulta mencionar a las modelos que posaron frente a estos lentes, poniendo su imagen al servicio del criterio estético de la época. Si bien la primera agencia para contratar profesionales de esta índole se inició en los Estados Unidos hacia 1923, ya el siglo anterior había contado con figuras que posaban para ser recreadas en el dibujo.

Por lo general las jóvenes que quedaron registradas transitaron también el mundo del cine, incipiente en los primeros tiempos. Entre los nombres que se destacan, figuran la preferida del Barón de Meyer, Ann Andrews quien posara por primera vez hacia 1919 para la revista Vogue; la actriz Miriam Hopkins, que pasó del cine mudo al sonoro, combinando ambas actividades.

Pero quizá la que más acaparó la atención en la primera mitad del siglo XX fue la sueca Lisa Fonssagrives (Bernstone, 1911-1992). Llegó a los Estados Unidos con la intención de convertirse en bailarina clásica pero fue capturada por la seducción del modelaje. Entre los 
años 30 y 50 se la consideró la modelo mejor cotizada. Su figura ilustró páginas de revistas como Vogue, Vanity Fair, Life y Time.

Su vida está ligada indisolublemente a la imagen, ya que se casó primero con el fotógrafo francés Fernand Fonssagrives y luego con el norteamericano Irvin Penn, con quien convivió hasta su muerte.

Debido a la extensa lista de figuras que fueron la cara visible de los diseñadores de la época, se menciona, a título informativo a Marlen Morehouse, Ann Andrews, Lily Tosch, Mary Taylor, Dorian Leigh, y Twiggy (la más revolucionaria de los años 60) como homenaje a todas aquellas que permitieron a través de su cuerpo, mostrar los estilos y características de este apasionante mundo.

Un "barón" en la indumentaria. Adolph de Meyer (1868-1949), es un nombre que marca un estilo en la fotografía de moda. El gran impacto de su obra se produce hacia 1915 , cuando se publica en la edición de Vogue, una fotografía de una dama de sociedad, Gertrude Vanderbilt, mostrándola con un estilo y distinción que llamó la atención de sus lectoras habituales.

Las revistas de moda estuvieron entre las primeras que hicieron un uso regular de la fotografía. En 1913, Vogue comenzó a publicar fotos realizadas para ella por Baron Adolf Meyer (sic); éste inició un estilo en el que la elegancia de las modas aparece desplegada junto a una sensibilidad fotográfica para las texturas. (Newhall, 2002, p. 263)

Aunque se supone que nació en París, pese a que algunos opinan que era de origen alemán, en 1893 se incorporó a la Royal Photographic Society de Londres, el mismo año que se considera que obtuvo su título nobiliario, si bien algunas fuentes mencionan que fue heredado de su abuelo. En esta institución adquirió un conocimiento artístico ligado a los movimientos de la época. El uso de filtros, reflejos luminosos y telas etéreas le confieren a su producción características especiales que demuestran el ideal de belleza de la época.

De Meyer transformó la fotografía de la moda, que era una actividad suplementaria para los fotógrafos, en una ocupación artística con dedicación exclusiva y que, además, era una elegante forma de vivir. Se produjo una especie de relación íntima social entre él y la mujer que era fotografiada. (Devlin, 1979).

Refinamiento y glamour. En 1902 se crea en Nueva York un movimiento que tendrá gran gravitación en el panorama de la fotografía mundial del siglo XX: Photo Secession, producto de la inspiración de Alfred Stieglitz (1864-1946) quien propone la realización de una "fotografía pura" distanciándose así de los cánones del pictorialismo de donde provenía el propio Stieglitz. Entre sus integrantes, se destaca el nombre de Edward Steichen, (18791973), de origen norteamericano, quien se incorpora al staff de las revistas Vogue y Vanity Fair a principios de los años 20 donde se desempeñará hasta 1937, convirtiéndose así en uno de los profesionales más destacados de la época, especialmente en el rubro moda, del 
cual fue un paradigma. La primera fotografía en color que se publicó en la portada de esa revista fue realizada por él en 1932.

Su perfeccionamiento en París, le abrió las puertas hacia otros aspectos tales como la dirección del Departamento de Fotografía del Museo de Arte Moderno (MoMA) en 1946 donde organizó una célebre exposición denominada The Family of Man en la cual establece un concepto del arte fotográfico, junto con un ideal moral, característico de lo que se conoce como fotografía humanista y que tanta incidencia tendrá en la segunda mitad del siglo XX.

El surrealismo en la moda. Emanuel Rudnitzky es el verdadero nombre del fotógrafo norteamericano conocido como Man Ray (1890-1976), el cual constituye un icono dentro de los movimientos artísticos del primer cuarto del siglo XX. Su talento sobrepasa los límites de la fotografía para introducirse en el movimiento surrealista, del cual formó parte en París entre las décadas del 20 y del 30. Y fue determinante para las películas que bajo este estilo se realizaron en dicha ciudad. Man Ray fue decisivo en la filmografía del cineasta español Luis Buñuel (1900-1983), que le debe al fotógrafo la posibilidad de difusión de su obra máxima Un chien andalou (1928).

Así lo comenta el propio Buñuel en sus memorias, con respecto a la película y en ocasión de conocerlo en París

Man Ray y Aragon (Louis, poeta surrealista 1897-1982)vieron la película al día siguiente en el Studio des Ursulines. A la salida, muy convencidos, me dijeron que había que darle vida cuanto antes, exhibirla organizar una presentación. (...) Había algo en el aire, como ocurre siempre. Pero tengo que añadir que, por lo que a mí respecta, mi encuentro con el grupo fue esencial y decisivo para el resto de mi vida. (1985, p. 104)

Considerado uno de los más destacados fotógrafos de moda, se destaca de su obra las producciones que realizara para Elsa Schiapparelli y Coco Chanel en ocasión de su trabajo en Harper's Bazaar, donde el erotismo prima sobre su mensaje.

Resulta interesante destacar que Man Ray abarca todo el espectro en cuanto al diseño, ya que se lo considera, además de fotógrafo, pintor, dibujante, diseñador gráfico, escultor, cineasta y tipógrafo. Actividades que le posibilitaron un mayor conocimiento de los diversos lenguajes estéticos de la época.

Su inquietud por la experimentación, le permitió aportar técnicas tales como la solarización y el rayograma, que incluyó en algunas de sus producciones de moda.

Sus elegidas transitan entre el misterio y la sensualidad, con el uso de recursos técnicos que subliman la imagen. Tal el caso de la realizada a la modelo y fotógrafa Lee Miller (Elizabeth, 1907-1977) en 1929, donde ella toma una pose atrevida para la época, con un fondo de sombras recortadas que acentúan el enigma de este personaje.

No menos importante fue la relación que tuvo con el pintor español Salvador Dalí (19041989), quien ocupa un lugar destacado en la moda por los diseños que realizara en los años 30 para la italiana Schipparelli, y que Man Ray fotografiara. 
Así, el impacto causado por las atrevidas propuestas, fueron reproducidos por otros diseñadores que incursionaron en este estilo. El vestido langosta, el de lágrimas o el sombrero zapato fueron algunos de los modelos que pusieron una nota de color en la conflictiva Europa de esos años.

La moda gana la calle. El cambio de valores y condiciones sociales alentaron modificaciones en el criterio de mostrar las tendencias del momento. Los fotógrafos se apropiaron de otros escenarios, no tan rígidos como un estudio, y lograron mostrar una mujer más dinámica y atrevida que podía sugerir sin dejar de mostrar sus diseños.

A esto contribuyó la evolución en la técnica y la invención de la cámara Leica, de pequeño formato que empieza a comercializarse en 1925 a través de la casa Leitz de Wetzlar; dicha cámara utilizó la película cinematográfica e implantó el llamado paso universal (formato 24 x $36 \mathrm{~mm}$ ) correspondiente a la superficie de dos fotogramas. En 1930 se presentó en la Feria Internacional de Liepzig, provista de un objetivo, con rollo de treinta y seis exposiciones.

Esta cámara marcó un antes y un después en el mundo periodístico y no solamente en el orden técnico. Por su práctico manejo será sinónimo de acción, rapidez y espontaneidad. Todo lo necesario para el vertiginoso mundo que se presentía. (Incorvaia, 2008, p. 89)

Dentro de este panorama el nombre del húngaro Martin Munkacski (1896-1963) sobresale por ser el primero que realiza en 1934 una producción de moda en exteriores para la revista Harper's Bazaar con la modelo en movimiento, tendencia que fue adoptada por otros profesionales como la norteamericana Tini Frissell (Antoinette Frissell Bacon, 19071988), dedicada también a la fotografía de guerra.

Ambos optaron por un estilo que conjugó dinamismo, encanto y actividad física. De la mujer pasiva que sus colegas presentaban, estos profesionales optaron por el criterio de realidad que exigía la época.

Los escenarios naturales se convirtieron así en el medio ideal para mostrar una moda más suelta y desinhibida. Si bien no fue fácil la imposición de este estilo, con los años fue muy recibido por las lectoras que se sentían identificadas con esta propuesta.

En cuanto a la producción de Munkacsi, Lilian Haberer comenta: "Su fotografía de acción se caracterizaba por la espontaneidad y por ángulos de enfoque poco convencionales (...) Desde ángulos extremos Munkacsi fotografiaba tanto modelos profesionales como seres corrientes durante sus actividades cotidianas, al aire libre y en movimiento". (1997, p. 455) En la edición del Gran libro de la Moda publicado por el diario Clarín se toma como referencia para definir el estilo de Fissell las palabras de la editora de modas Bettina Ballard, al mencionar que:

Frissell se especializaba en tomas en exteriores de ropa deportiva. Con sus contactos sociales, su pasión por el esquí, que la llevaba a Suiza todos los inviernos, y su disposición para viajar en cualquier momento a cualquier lugar, era una combinación de fotógrafa-editora. (2011, No. 5) 
Estilo y humanidad. El nombre de Richard Avedon (1923-2004) conjuga seducción, misterio y sensualidad en una combinación que hace de sus obras testimonios visuales de gran valor antropológico. De origen norteamericano, en 1944 ingresa en Harper's Bazaar, gracias a su director, Alexey Brodovitch (1898-1971) que fuera encargado del Departamento de Arte de la revista entre 1934 y 1958, y es considerado un experimentado diseñador gráfico y fotógrafo, formador de los principales profesionales de la época.

Avedon y Brodovitch establecieron una relación de amistad que perduró durante años y que le permitió también la edición de su libro Observaciones, con textos de Truman Capote. A partir de allí, numerosas publicaciones componen su producción, donde la humanidad ocupa un lugar preferencial. En 1994 el Museo Ludwig de Colonia, Alemania, realizó una muestra retrospectiva, donde se integraron además sus fotografías de moda.

Dentro de este ámbito Dovima con elefantes, traje de noche Dior, Cirque d'Hiver, realizada en 1955, constituye un hito en su carrera.

Es una de las más célebres fotografías de moda de Avedon y ciertamente una de las más insólitas. Su interés reside simultáneamente en el inusitado contraste y la impresión general de una inefable elegancia. Esa fotografía marca el comienzo de una nueva era en la puesta en escena fotográfica. (MiBelbeck, 1997, p. 32)

Alain Dister, en el artículo publicado en la revista Connaissance des Arts $N^{o} 16$, comenta a propósito de su obra que si bien fue famoso por sus clichés de moda chic, sus retratos sobre fondos blancos son una marca de fábrica. Considera que ha sido también un fotógrafo retratista que supo captar la vida cotidiana, a veces difícil, de sus contemporáneos. (2008).

Un estilo intimista. Irvin Penn (1917-2009), nacido en los Estados Unidos de América, accede al mundo de la gráfica a través de sus estudios realizados también con Alexey Brodovitch, trabajando en la Philadelphia Museum School of Industrial Art. Instalado en Nueva York en 1938, publica su primera tapa para Vogue en 1943. A partir de allí, trabajó regularmente en esta revista y otras de diversos países.

Una de sus características más destacadas para la realización de este tipo de fotografías fue la composición en interiores, desentendiéndose de las tomas callejeras y de las de exterior, a diferencia de su contemporáneo, Richard Avedon.

Se destacan en su producción las series que realizara precisamente para Vogue, como la efectuada en 1949, caracterizando en cinco imágenes la moda de la primera mitad del siglo XX.

Permaneció fiel durante toda su vida a las tomas en estudio y bajo determinadas condiciones de iluminación, de manera que los conocedores pueden distinguir las fotografías tomadas en París, por ejemplo, de aquellas realizadas en Nueva York sobre los mismos temas. (...) La personalidad de la modelo tiene lugar importante en su fotografía de moda, y a menudo, las imágenes están muy próximas del retrato. (MiBelbeck, 1997, p. 482) 
Personalidades como Pablo Picasso, Jean Cocteau, las consideradas súper modelos Lisa Fonsagrives y Dorian Leigh, posaron su seducción, personalidad y encanto frente al lente de Penn, donde se destaca de forma directa la intimidad que une al fotógrafo con su modelo. Se podría decir que esa disciplina estética que manejó y la economía de los medios formales, le valieron un estilo muy personal que ha perdurado en el tiempo.

La ruptura con las convenciones. El nombre de Helmut Newton (1920-2004) ha generado múltiples contradicciones en cuanto al mensaje que se observa en sus imágenes. Nacido en Alemania, estudió fotografía en la escuela berlinesa de Iva, reconocida por sus retratos de moda y desnudo, conjunción que el artista supo explotar en sus composiciones. Trabajó para las ediciones francesa, inglesa, norteamericana e italiana de la revista Vogue, y también en Elle, Marie Claire, Jardin de Modes, American Playboy, Nova y Queen. A su vez, realizó reportajes fotográficos para Stern y Life, el magazine nacido en 1936 en los Estados Unidos que impuso el uso de la fotografía como eje comunicacional de su información.

De este modo lo define MiBelbeck

...creó un nuevo estilo de fotografía de moda y de desnudo, cuyo éxito está indudablemente emparentado con su profunda sensibilidad antes los signos y el espíritu de nuestra época. Su combinación de actitudes agresivas y sumisión voluntaria, sumada a su preferencia por mujeres altas, de marcados huesos y seguras de sí mismas toca el centro del dilema en el que todavía se encuentran las mujeres y los movimientos feministas: revindicar su participación en las decisiones de la sociedad, sin renunciar sin embargo a su identidad femenina... (1999, p. 470)

Su lente registró, rompiendo convenciones, las propuestas de diseñadores de la importancia de Ives Saint-Laurent, Claude Montana o Karl Lagerfeld.

\section{Eterna moda, eterna}

Más allá de estos estilos definidos en cuanto a la captura de la imagen, la moda sufrió cambios interesantes durante el transcurso del siglo. Los años posteriores a la Segunda Guerra Mundial redefinieron la figura femenina con la aparición del prêt-à-porter, más asequible para una sociedad que buscaba su recomposición.

$\mathrm{Al}$ respecto, Pepe Baeza considera:

Los años treinta, cuarenta y cincuenta vieron crecer a algunos de los mejores fotógrafos experimentales, en las páginas de la llamada prensa glamourosa, de la mano de algunos de los mejores directores de arte y editores gráficos de la historia de la comunicación gráfica: Blumenfeld, Matter, Brodovitch... Se generaron así productos visuales que, en ocasiones, resistirían mucho mejor que las revistas de reportaje el acoso de la televisión por la captación de la audiencia. (2001, p. 103) 
Los sesenta y los setenta ubicó en primer plano a la juventud que buscaba un modo de participación más activo en la sociedad y cuyos atuendos dieron cuenta de los profundos cambios que se instalaron. Así la "cultura underground" (Szpunberg), que se manifestara a través de la moda con el uso general de jeans, polleras floridas, cabellos largos, si bien fue derrotada por el consumismo, transformó formas de comportamiento, tanto en la vida social como en la privada.

"La preocupación por la libertad, el derecho al uso del propio cuerpo, la revalorización de la naturaleza y la búsqueda de una nueva vida germinaron durante aquella inolvidable década y aún siguen siendo cuestiones candentes". (1982, p. 24)

Los años setenta presentaron otras posturas y gestos. Las propuestas fotográficas exhibieron a mujeres activas mostradas en situaciones dominantes, para resaltar los logros obtenidos en la sociedad, tanto desde las actividades laborales como desde la exaltación de su cuerpo a través del erotismo.

El último cuarto del siglo XX se destaca por la influencia de la moda oriental, representada a través de diseñadores como Issey Miyake, Rei Kawakubo, Kenzo Takada y Johjo Yamamoto quienes se posicionaron en el panorama de la moda mundial.

Palabras tales como costura tecnológica, deconstrucción, diseñador gráfico, entre otras se posicionaron en la escena de la moda, dotándola de nuevas expresiones que vieron su consecuencia en los denominados "reyes sin corona", como se ha llamado a Karl Lagerfeld, John Galliano, Marc Bohan, Alexander McQueen, entre los más destacados que trabajaron para importantes marcas como Yves Saint Laurent, Christian Dior y Givenchy, por ejemplo.

El advenimiento de grandes modelos y actrices como protagonistas de la moda, no hizo más que profundizar lo que desde siempre la fotografía de moda mostró: encanto, seducción, refinamiento. De este modo Cindy Crawford, Claudia Schiffer, Naomí Campbell se convirtieron en la cara visible de las firmas mencionadas.

La imagen fotográfica acompañó estos cambios generando composiciones más atrevidas en cuanto a la puesta en escena y el manejo de planos. Encuadres diferenciados aportaron la cuota de exotismo y misterio que este rubro de la fotografía precisaba para profundizar su mensaje.

A su vez, resulta interesante reflexionar acerca de los profesionales seleccionados, ya que prácticamente todos ellos abordaron el criterio de una formación que no se encerró en la fotografía, sino que abarcaron otras disciplinas que hacen al universo audiovisual, como la pintura, el cine o el diseño gráfico. Esta formación refuerza la idea de la importancia de una capacitación que permita ahondar la estética.

Hoy la fotografía de moda como la publicitaria tienen aliados inmensurables en la digitalización y el Photoshop. Los profesionales actuales los utilizan para dar una mejor y acabada imagen de su producción, pero sólo son herramientas condicionadas por la mano del fotógrafo.

Así lo define Joan Fontcuberta:

La tecnología digital parece haber destapado la caja de Pandora y se hace acreedora de numerosas críticas. Hay que recordar una vez más que la técnica no es más que un conjunto de herramientas que por sí mismas no 
son merecedoras de un juicio moral aunque encierren una proclividad en algún sentido. (2011, p. 131)

Pero lo que estos recursos no podrán suplantar es la sutileza y el glamour que la fotografía de moda presenta. De la habilidad y destreza de estos pioneros surgió un estilo que se manifiesta en los profesionales actuales, los cuales recogieron el guante en este ámbito de encanto y seducción.

Los seres visuales que conforman este siglo XXI precisan de la imagen para poder interpretar el mensaje. Aun saturados de ellas, se necesita de ese soporte como eje de una comunicación implícita en nuestra cultura.

En relación con este tema Martín Jolie manifiesta:

Podemos percibir, sin embargo, que la “imagen”, lejos de ser una plaga amenazante y contemporánea, es un medio de expresión y de comunicación que nos vincula con las tradiciones más antiguas y más ricas de nuestra cultura. Su lectura, incluso la más inocente y la más cotidiana, cultiva en nosotros una memoria que sólo demanda reactivarse un poco para convertirse en una herramienta de autonomía más que de pasividad. (2009, p. 147)

Gracias entonces a ella conocemos, apreciamos y nos socializamos. La fotografía de moda, por su parte, permitió acercar tendencias y estilos abriendo el camino en el infinito mundo de la comunicación actual. ¡Bienvenida sea!

\section{Bibliografía}

Alemán, J. (edic. literaria) (2011). El gran libro de la moda. Buenos Aires. Editorial Sol90media. Diario Clarín.

Baeza, P. (2001). Por una función crítica de la fotografía de prensa. Barcelona, Gustavo Gili. Buñuel, L. (1985). Mi último suspiro (Memorias). Barcelona. Plaza \& Janes Editores.

Devlin P. (1979). Los primeros sesenta años de la fotografía de moda, s/d.

Dister, A. Richard. (2008). Avedon, l'essentiel du regard. Richard Avedon au Jeu de Paume.. París. Connaissance des Arts Photo 16

Fontcuberta, J. (2011). La cámara de Pandora. La fotografi@ después de la fotografía.

Barcelona, Gustavo Gili.

Henckmann, W. Lotter, K (eds.) (1998). Diccionario de estética. Barcelona, Grijalvo Mondadori.

Incorvaia, M. (2008). La fotografía. Un invento con historia. Buenos Aires, Ediciones del Aula Taller.

Joly, M. (2009). Introducción al análisis de la imagen. Buenos Aires, La Marca.

MiBelbeck, R. Scheps, M. (edit.) (1997). La fotografía del siglo XX. Museum Ludwig Colonia.

Colonia. Taschen

Newhall, B. Historia de la Fotografía (2002). Barcelona, Gustavo Gili.

Peter, S. (editor). Icons of Photography (2005). New York, Prestel-Verlag. 
Szpunberg, A. (1982). Los hechos políticos del siglo XX. El movimiento hippie, los caminos de la contracultura. Madrid, Hyspamérica.

Summary: Just as the invention of photography changed the look of the society, its irruption in fashion allowed the visualization of a world of refinement that astonished the twentieth century women. With the advent of the printing press, and before the arrival of magazines aimed at a specific audience, photographers were able not only to show their professional skills but to capture fashion world at its wider dimension.

Names like Edward Steichen, Man Ray, Helmut Newton, Richard Avedon, among others, showed their talent inspired by the artistic trends that emerged in the first half of the twentieth century and extending to the present. This paper analyzes their work related to the structure of their images and the different features of their proposals.

Key words: fashion - glamour - photography - print media - avant-garde - aesthetics.

Resumo: Assim como a invenção da fotografia mudou a mirada da sociedade, sua irrupção na moda permitiu visualizar um mundo de refinamento que as mulheres do século XX contemplaram admiradas. Com a chegada da imprensa gráfica, e das revistas destinadas a um público específico, os fotógrafos tiveram a possibilidade não somente de dar a conhecer suas próprias capacidades profissionais, senão de dotar à indumentária de imagens onde o artístico e o glamour se mostraram em toda sua dimensão.

Nomes como Edward Steichen, Man Ray, Helmut Newton, Richard Avedon, entre outros, possibilitaram mostrar seu talento, inspirados nas correntes artísticas que surgiram na primeira metade do século XX, e se prolongam até hoje. Este trabalho analisa suas respectivas obras em relação com a estrutura de suas imagens e as diferentes características de suas propostas.

Palavras chave: moda - glamour - fotografia - imprensa gráfica - vanguardas - estética. 